\title{
RANCANG BANGUN GAME EDUKASI SINAU BASA LAN AKSARA JAWA (SIBAKJA) BERBASIS ANDROID MENGGUNAKAN ADOBE FLASH CS6 UNTUK SISWA SEKOLAH DASAR DI KEBUMEN
}

\author{
${ }^{1}$ Triyono, ${ }^{2}$ Apit Priatna \\ E-mail : 'triyono9591@gmail.com, ${ }^{2}$ apit.priatna@dosen.rosma.ac.id
}

\begin{abstract}
Abstrak
Bahasa jawa ialah sebuah kebudayaan yang sangat perlu dilestarikan karena membuat Indonesia kaya akan ragam bahasa. Bahasa jawa merupakan bahasa yang digunakan untuk berkomunikasi oleh sebagian besar masyarakat jawa khususnya di Kebumen. Pada umumnya siswa Sekolah Dasar masih kesulitan menggunakan bahasa jawa yang baik dan benar serta sulitnya memahami aksara jawa dikarenakan kurangnya media untuk belajar. Bahasa jawa akan lebih mudah di ajarkan pada anak-anak apabila menggunakan suatu media yang menyenangkan, efektif, konstekstual, bermakna dan efisien yang dikemas dalam suatu game edukasi. Dalam hal ini yaitu media permainan sekaligus pembelajaran bahasa jawa yang ditanamkan dalam handphone pintar atau smartphone yang sudah menggunakan android dalam sistem operasinya, aplikasi ini dibangun menggunakan Adobe Flash CS6 dengan Action Script 3.0 sebagai bahasa pemrogramannya merupakan cara yang paling ampuh dalam mengenalkan bahasa dan aksara jawa kepada anak tingkat Sekolah Dasar, karena dengan metode seperti itu tetap akan memberikan suatu ilmu pengetahuan kepada anak-anak dengan cara bermain game dan setelah itu bisa secara perlahan mengajak anak tersebut untuk lebih dalam mempelajari bahasa jawa dan mengajak untuk melestarikannya.
\end{abstract}

Kata Kunci : Bahasa Jawa, Aksara Jawa, Game edukasi, Android, Adobe Flash CS6.

\begin{abstract}
Abstrack
Javanese language is a culture that really needs to be preserved because it makes Indonesia rich in a variety of languages. Javanese language is the language used to communicate by most Javanese people, especially in Kebumen. In general, elementary school students still have difficulty using good and correct Javanese language and the difficulty of understanding Javanese script due to the lack of media for learning. Javanese language will be more easily taught to children when using a media that is fun, effective, contextual, meaningful and efficient which is packaged in an educational game. In this case the game media as well as learning Javanese language embedded in smart phones or smartphones that already use Android in the operating system, this application is built using Adobe Flash CS6 with Action Script 3.0 as its programming language is the most effective way to introduce Javanese language and characters. to elementary school children, because with such a method it will still provide knowledge to children by playing games and after that can slowly invite the child to learn more about Javanese language and invite to preserve it.
\end{abstract}

Keywords: Javanese, Javanese script, educational game, Android, Adobe Flash CS6.

Jurnal Interkom: Jurnal Publikasi Ilmiah Bidang Teknologi Informasi dan Komunikasi

Volume 14 Nomor 04 Bulan Januari - Tahun 2020 


\section{Pendahuluan}

Perkembangan suatu teknologi dan komunikasi yang begitu pesat sekarang ini berpengaruh terhadap perkembangan suatu aplikasi diantanya game yang merupakan suatu hiburan diantaranya game edukasi. Pembuatan game edukasi berbasis android yang dibuat menggunakan Adobe Flash Profesional CS6 dengan memanfaatkan action script 3.0 agar game dapat dimaikan secara offline merupakan suatu teknologi yang sedang berkembang saat ini. Game edukasi yang dapat dimaikan secara offline di smartphone dapat menjadi suatu media pembelajaran bagi siswa Sekolah Dasar khususnya siswa kelas tiga sampai dengan kelas enam dengan memanfaatkan suatu media smartphone.

Kalangan siswa Sekolah Dasar khususnya di daerah Kebumen mengalami kesulitan dalam memahami aksara jawa mulai dari mengenal huruf Jawa sampai dengan membentuk kata dan kalimat dengan sandhangan beserta aturanaturan dalam penulisannya. Bagi kalangan siswa Sekolah Dasar masih banyak yang kurang mengetahui ataupun kurangnya pengetahuan tentang nama hewan dan tumbuhan dalam bahasa jawa, yang paling utama adalah dalam berkomunikasi dengan bahasa jawa yang santun dan benar harus diajarkan sejak dini. Bahasa jawa merupakan bahasa yang santun dan perlu dilestarikan agar tidak hilang, hal tersebut di karenakan bahasa jawa memiliki unggah-ungguh basa atau undha-usuk basa yang berarti tingkat perkataan bahasa jawa. Tingkat perkataan bahasa jawa mencerminkan kesantunan dari masyarakat jawa.

Oleh karena itu dibutuhkan sebuah inovasi untuk membuat siswa Sekolah Dasar dapat mempelajari aksara jawa, pengenalan nama hewan dan pepohonan dalam bahasa jawa untuk siswa Sekolah Dasar serta dapat mempelajari bahasa jawa krama dengan mudah dan menyenangkan pada umumnya, salah satunya yaitu dengan menggunakan sebuah media game edukasi yang menarik dengan model pembelajaran pengenalan bahasa dan aksara jawa serta dapat dapat mengetahui nama hewan dan pepohonan dalam bahasa jawa maupun pada umumnya bisa memahami bahasa dan aksara jawa yang baik benar dan disertai dengan quiz untuk mendalami pemahaman sehingga dapat membuat siswa merasa mudah dan senang dalam belajar.

Berdasarkan uraian diatas, penulis tertarik untuk mengusulkan pembangunan sebuah aplikasi game edukasi yang bisa membantu kalangan siswa Sekolah Dasar khususnya di Kebumen dalam belajar bahasa jawa dengan mudah dan menyenangkan. Oleh karena itu penulis mengambil judul "Rancang Bangun Game Edukasi Sinau Basa lan Aksara Jawa (Sibakja) berbasis Android menggunakan Adode Flash CS6 untuk Siswa Sekolah Dasar di Kebumen".

\section{Tinjauan Pustaka}

\section{Pengertian Rancang Bangun}

Menurut Bambang (2013:27), "rancang bangun adalah proses membuat sistem yang baru atau mengganti maupun memperbaiki sistem yang sudah ada baik secara keseluruhan maupun hanya sebagian".

\section{Pengertian Aplikasi}

Menurut Hengky (2010:14), "aplikasi ialah Suatu perangkat lunak yang dibuat dengan tujuan untuk melayani suatu kebutuhan dari beberapa aktifitas seperti halnya sistem perniagaan, pelayanan masyarakat, game, periklanan maupun semua proses yang hampir dilakukan manusia".

\section{Pengertian Game}

Menurut Anggara dalam Zulfadli Fahrul Rozi (2010:6) "game ialah Suatu permainan yang dapat dimainkan dan terdapat aturan tertentu dan biasanya dalam konteks yang tidak serius dan bertujuan refreshing."

\section{Pengertian Edukasi}

Menurut Muhammad Saroni (2011) "edukasi berarti pendidikan yang merupakan proses yang berlangsung dalam kehidupannya sebagai usaha untuk menyeimbangkan diri dari suatu kondisi luar".

\section{Pengertian Game Edukasi}

Menurut Costikyan (2013:20), "game adalah sebentuk karya seni di mana peserta, yang disebut pemain, membuat keputusan untuk mengelola sumber daya yang dimilikinya 
melalui benda di dalam game demi mencapai tujuan".

\section{Pengertian Smartphone}

Menurut Anonim (2012) menjelaskan bahwa "Smartphone (telepon pintar) adalah telepon genggam yang mempunyai kemampuan tingkat tinggi dengan fungsi yang menyerupai komputer".

\section{Android}

Menurut Murya Yosep (2014) "Android merupakan Suatu sistem operasi yang berbasis Linux dan digunakan untuk telepon seluler (mobile) seperti telepon pintar (smartphone) dan komputer tablet (PDA)".

\section{Adobe Flash Profesional CS6}

Menurut A. Jibril (2011:3), “Adobe flash merupakan salah satu program animasi desain grafis yang sering digunakan oleh para desainer dengan menghasilkan karya profesional, terlebih pada bidang animasi”.

\section{Action Script 3.0}

Action Script adalah bahasa pemrograman yang dibuat berdasarkan ECMA Script, yang digunakan dalam pengembangan situs web dan perangkat lunak menggunakan platform Adobe Flash Player.

\section{Adobe Photoshop}

Photoshop adalah perangkat lunak editor citra buatan Adobe Systems yang dikhususkan untuk pengeditan foto/gambar dan pembuatan efek, dengan software ini kita dapat mengedit gambar/foto dengan semau kita, dan satusatunya software pengolah gambar yang handal.

\section{Adobe Audition}

Adobe Audition adalah perangkat lunak yang dirilis oleh Adobe Inc, perangkat lunak ini berfungsi untuk merekam, mengedit suara dalam bentuk digital yang berbasis Windows.

\section{Version Control}

Version control adalah sebuah sistem yang mencatat setiap perubahan terhadap sebuah berkas atau kumpulan berkas sehingga pada suatu saat penulis dapat kembali kepada salah satu versi dari berkas tersebut.

\section{Unified Modeling Language (UML)}

Menurut Nugroho, (2010:6) "Unfied

Modelling Language (UML) merupakan suatu bahasa pemodelan yang digunakan untuk sistem maupun perangkat lunak yang berparadigma (berorientasi objek)".

\section{Basa Jawa}

Basa jawa yang berarti Bahasa Jawa merupakan suatu bahasa daerah yang termasuk bagian dari kebudayaan nasional Indonesia, yang digunakan oleh masyarakat jawa khususnya di daerah Kebumen Jawa Tengah dan juga masyarakat Jawa Timur. Menurut Supartinah (2010: 24). Bahasa Jawa memiliki fungsi dan kedudukan penting bagi masyarakat penuturnya. Bahkan keberadaan bahasa Jawa juga turut memberikan dukungan kepada bahasa Indonesia. Fungsi bahasa Jawa yang tadinya lebih luas meliputi sampai pada bahasa resmi di kalangan pemerintahan dan ilmu pengetahuan di sekolah sekarang menjadi lebih singkat.

\section{Aksara Jawa}

Dalam jurnalnya Arismadhani dkk (2013) menuliskan bahwa Aksara Jawa ini syarat akan banyak makna, karena didalam tiap-tiap huruf Aksara Jawa mempunyai makna tersendiri yaitu adanya hubungan kehidupan antara manusia dengan sang pencipta dan hubungan manusia dalam kehidupan sosial.

\section{Metodologi Penelitian}

Metodologi penilitian ini menjelaskan mengenai media pengumpulan data dan metode perancangan data.

\section{Pengumpulan Data}

Pengumpulan data yang digunakan untuk mendapatkan data dengan menggunakan sebagai berikut:

1. Observasi

Penulis melakukan observasi ke beberapa Sekolah Dasar di kabupaten Kebumen untuk melihat secara langsung kegiatan belajar siswa serta kurikulum dan buku-buku yang digunakan untuk belajar khususnya pelajaran Bahasa Jawa. 


\section{Kuisioner}

Penulis mengumpulkan data dengan kuisioner yang dilakukan kepada beberapa siswa dari kelas tiga sampai kelas enam tingkat pendidikan Sekolah Dasar di beberapa desa dari Kecamatan Buluspesantren, Kabupaten Kebumen dengan menggunakan 10 soal kuisioner dengan 5 pilihan yang diajukan yaitu Sangat Setuju, Setuju, Netral, Tidak Setuju dan Sangat Tidak Setuju, dan juga dilakukan kepada kepada salah satu guru di Sekolah Dasar tersebut untuk pengujian terhadap aplikasi yang sudah jadi untuk menguji sistem sehingga penulis yakin bahwa aplikasi yang dibuat akan berguna bagi kalangan siswa Sekolah Dasar di Kebumen.

3. Studi Pustaka

Penulis mengumpulkan data dengan cara membaca buku-buku dan literatur sesuai dengan pembahasan yang diperlukan. Pada penelitian ini penulis memilih Studi Pustaka untuk dijadikan sebagai referensi dalam pembuatan game edukasi "sibakja".

\section{Metode Perancangan}

Penelitian ini penulis menggunakan metode prototype:

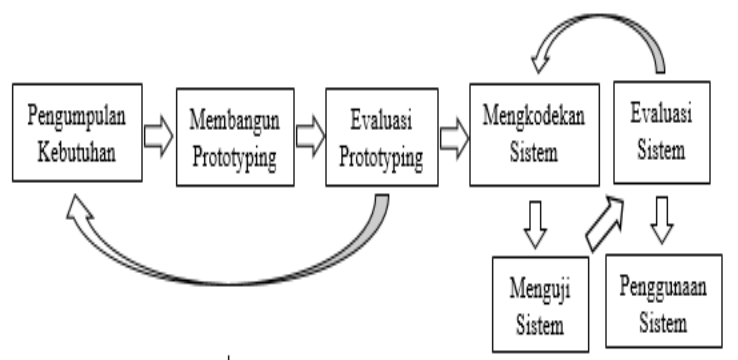

Gambar 1 Model Prototype

1. Pengumpulan Kebutuhan

Pembangunan sistem informasi memerlukan penyelidikan dan analisis mengenai alasan timbulnya ide atau gagasan untuk membangun suatu sistem ataupun aplikasi. Pengumpulan kebutuhan dilakukan untuk melihat berbagai komponen yang dipakai sistem yang sedang berjalan meliputi hardware, software, jaringan dan sumber daya manusia.

2. Membangun prototyping

Membangun prototyping dengan membuat suatu perancangan sementara yang terfokus pada penyajian game yang dibuat dengan membuat desain sistem input dan format outputnya. Membangun prototyping sistem membutuhkan peralatan berupa alat alat perancangan proses dan alat perancangan data. Alat perancangan proses yang digunakan dalam tahapan ini merupakan metode perancangan untuk mendesain sistem yaitu metode UML (Unified Moddelling Language) dengan standar merancang sebuah sistem yang digambarkan melalui beberapa diagram yaitu:
a. Use Case
b. Activity diagram
c. Squence diagram
d. Class diagram

\section{Evaluasi protoptyping}

Evaluasi protoptyping dilakukan untuk mengetahui apakah desain sistem dengan prototyping yang dibangun telah sesuai dengan keinginannya. Jika sudah sesuai maka langkah 4 akan diambil. Jika tidak prototyping direvisi dengan mengulang langkah 1, 2, dan 3.

4. Mengkodekan sistem

Untuk dapat dimengerti mesin yaitu komputer maka suatu desain harus diubah ke bentuk yang dapat dimengerti mesin yaitu dengan proses coding. Untuk proses ini penulis menggunakan Adobe flash CS6 dengan bahasa pemrograman Action Script 3.0

5. Menguji sistem

Untuk mengamati hasil dari suatu program penulis menggunakan sistem Black Box Testing yaitu pengujian yang didasarkan pada detail aplikasi seperti tampilan aplikasi, fungsi-fungsi yang ada pada aplikasi dan kesesuaian alur fungsi dengan alur proses yang diinginkan dalam perancangan aplikasi game edukasi "Sibakja" yang dibuat.

6. Evaluasi Sistem

Langkah ini bertujuan untuk mengevaluasi sistem yaitu apakah sistem dapat berjalan dengan baik dan benar serta dapat membantu kalangan siswa Sekolah Dasar untuk belajar bahasa dan aksara jawa dengan mudah dan menyenangkan. 
7. Menggunakan sistem

Setelah prototype diterima maka pada tahap ini merupakan implementasi sistem atau menggunakan sistem yang siap dioperasikan.

\section{Hasil Penelitian dan Pembahasan}

\section{Implementasi Sistem}

1. Tampilan Halaman Pembuka

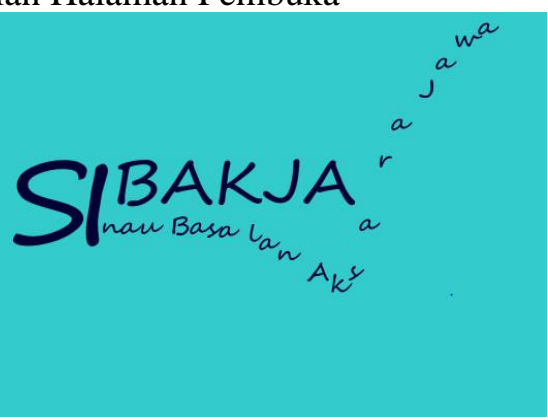

Gambar 1 Tampilan Halaman Pembuka

2. Tampilan Halaman Menu Utama

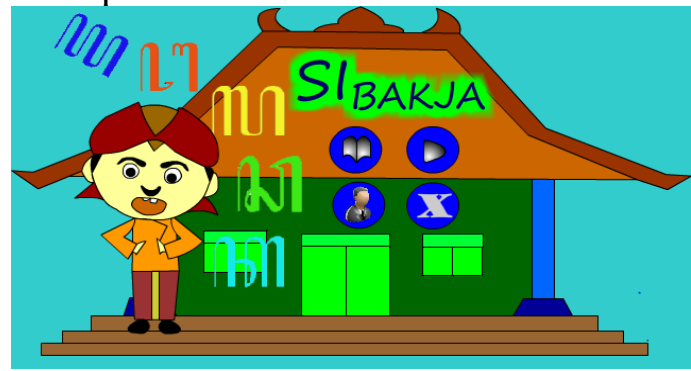

Gambar 2 Tampilan Halaman Menu Utama

3. Tampilan Halaman Menu Materi

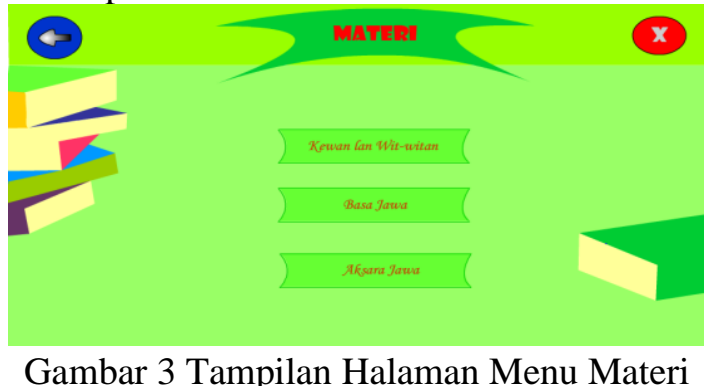

4. Halaman Menu Kewan lan Wit-witan

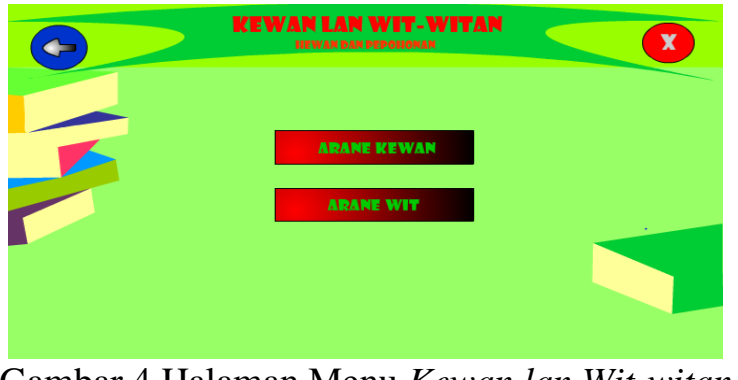

Gambar 4 Halaman Menu Kewan lan Wit-witan

5. Tampilan Halaman Arane Kewan

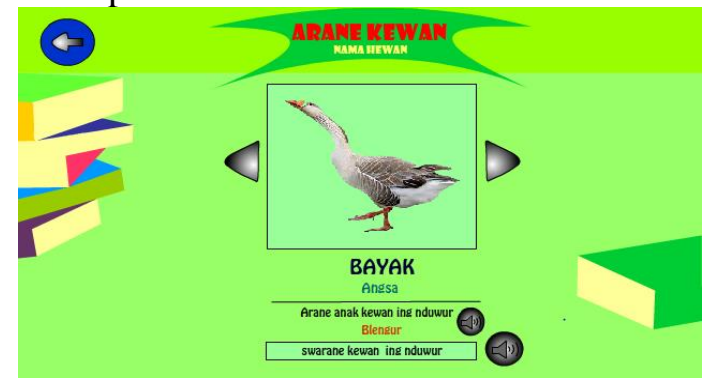

Gambar 5 Tampilan Halaman Arane Kewan

6. Tampilan Halaman Arane Wit

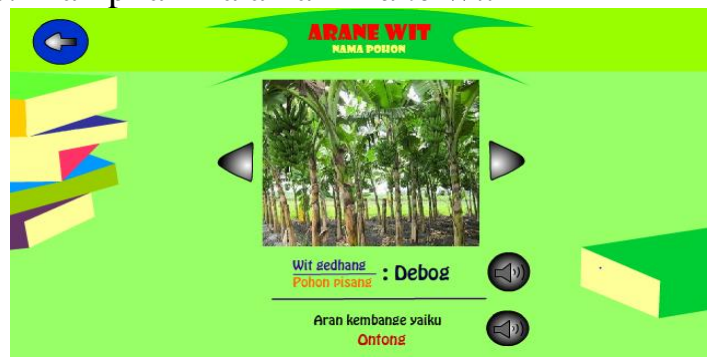

Gambar 6 Tampilan Halaman Arane Wit

7. Tampilan Halaman Basa Jawa

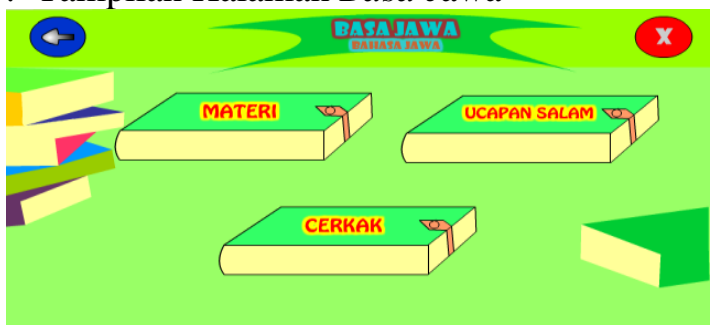

Gambar 7 Tampilan Halaman Basa Jawa 
8. Tampilan Halaman Materi

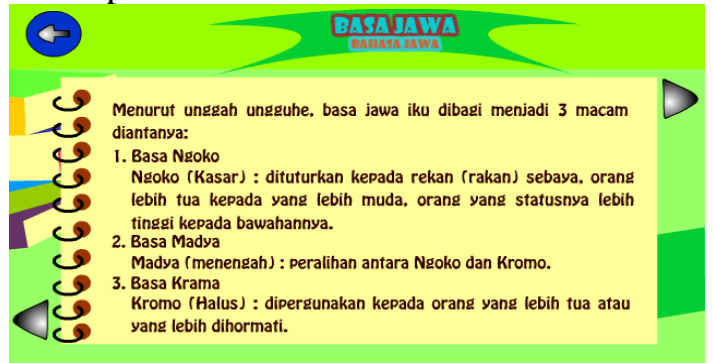

Gambar 8 Tampilan Halaman Materi basa jawa

9. Tampilan Materi basa jawa bentuk kata (tembung)

4.
\begin{tabular}{|c|c|c|c|c|}
\hline No & Ngoko & Krama Madya & Krama Inggil & Arti \\
\hline 1 & Abang & Abrit & Abrit & Merah \\
\hline 2 & Adoh & Tebih & Lebih & Jauh \\
\hline 3 & Aku & Kula & Kawula & Saya \\
\hline 4 & Alis & Alis & Imba & Alis \\
\hline 5 & Anak & Yoga & Putra & Anak \\
\hline 6 & Awak & Badan & Salira & Badan \\
\hline 7 & Bali & Mathuk & Kondur & Pulang \\
\hline 8 & Banyu & Toya & Toya & Air \\
\hline 9 & Bathuk & Bathuk & Palarapan & Dahi \\
\hline 10 & Bener & Leres & Kasingqahan & Benar \\
\hline
\end{tabular}

Gambar 9 Tampilan Materi basa jawa bentuk kata (tembung)

10. Tampilan Halaman Menu Ucapan Salam

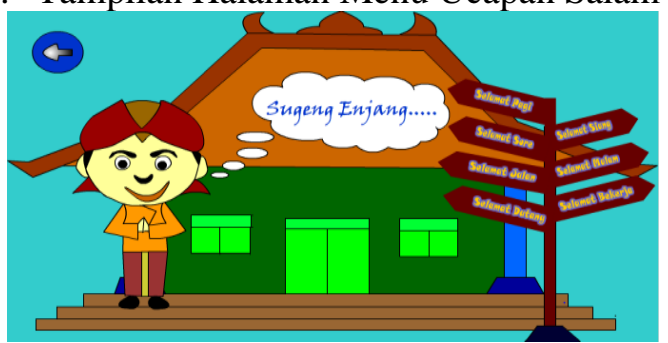

Gambar 10 Tampilan Halaman Menu Ucapan Salam

11. Tampilan Halaman Menu Cerkak

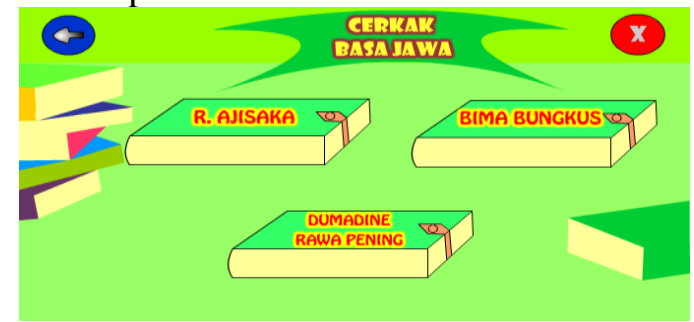

Gambar 11 Tampilan Halaman Menu Cerkak
12. Tampilan Halaman Cerkak Raden Ajisaka

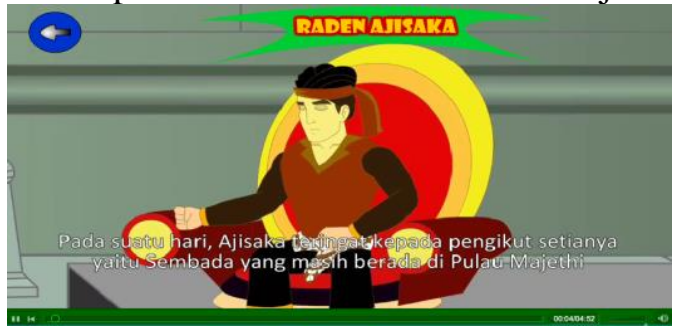

Gambar 12 Tampilan Halaman Cerkak Raden Ajisaka

13. Tampilan Halaman Cerkak Bima Bungkus

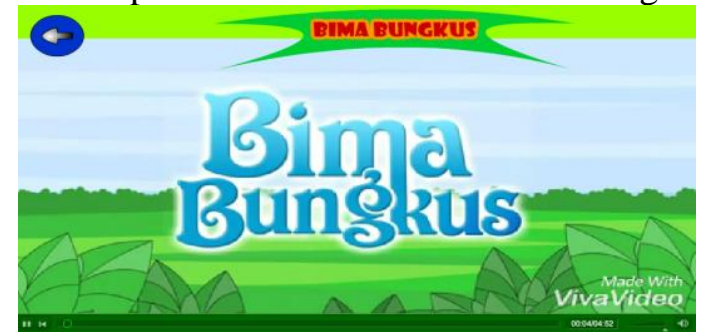

Gambar 13 Tampilan Halaman Cerkak Bima Bungkus

14. Tampilan Halaman Cerkak Dumadine Rawa Pening

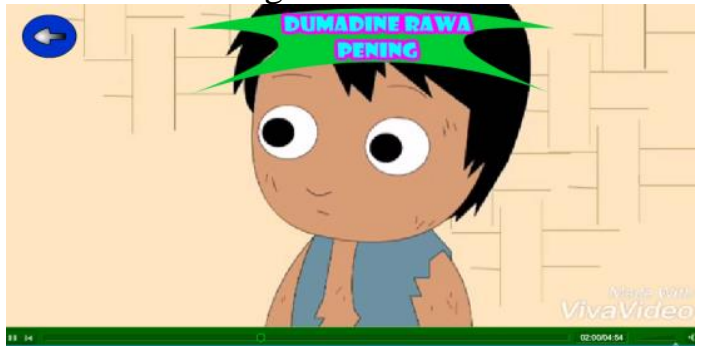

Gambar 14 Tampilan Halaman Cerkak Dumadine Rawa Pening

15. Tampilan Halaman Menu Aksara Jawa

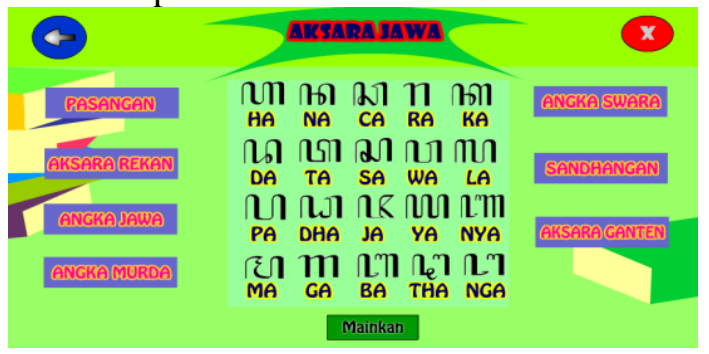

Gambar 15 Tampilan Halaman Menu Aksara Jawa 
7. Tampilan Halaman Aksara Jawa

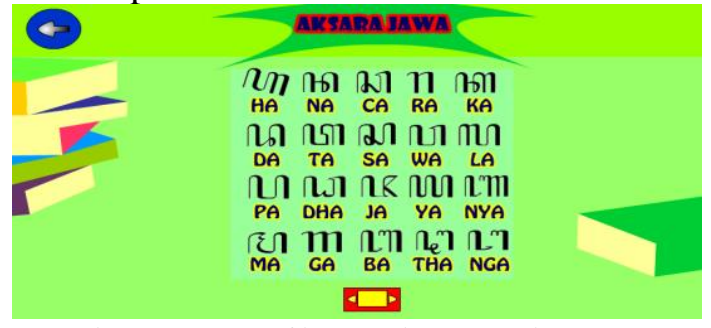

Gambar 16 Tampilan Halaman Aksara Jawa

8. Tampilan Halaman Aksara Jawa 1

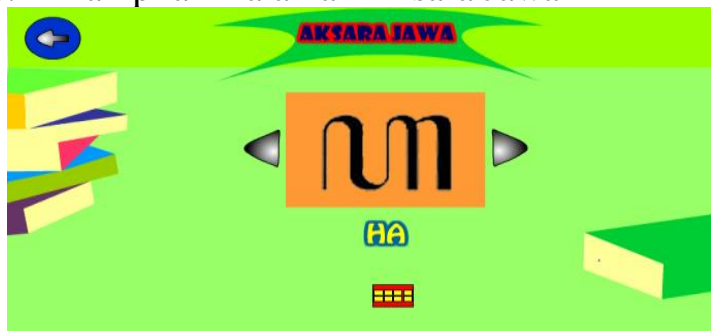

Gambar 17 Tampilan Halaman Aksara Jawa 1

9. Tampilan Halaman Pasangan

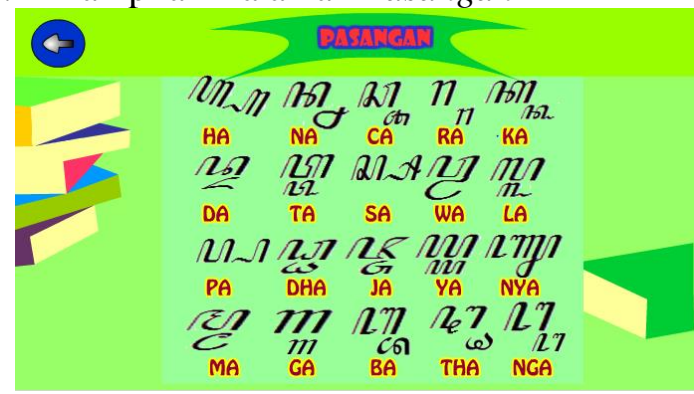

Gambar 18 Tampilan Halaman Pasangan

10. Tampilan Halaman Aksara Rekan

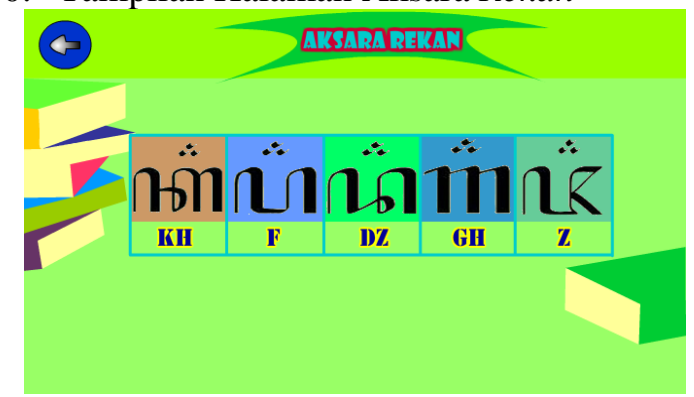

Gambar 19 Tampilan Halaman Aksara Rekan
11. Halaman Angka Jawa

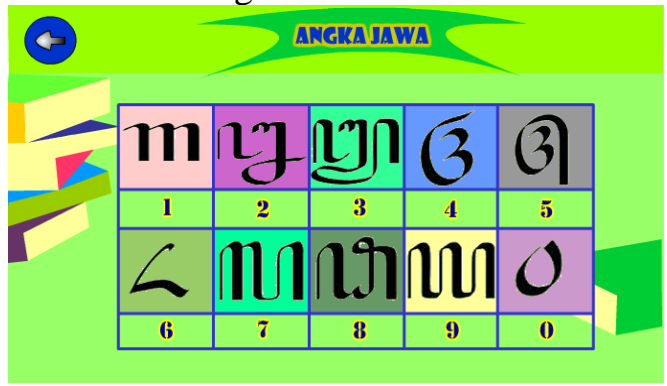

Gambar 20 Halaman Angka Jawa

12. Halaman Angka Murda

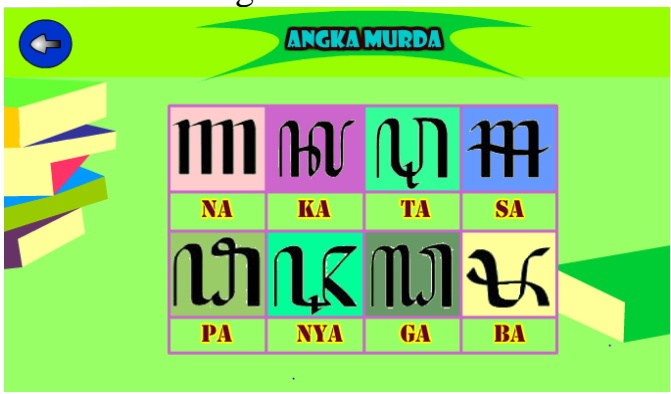

Gambar 21 Halaman Angka Murda

13. Halaman Angka Swara

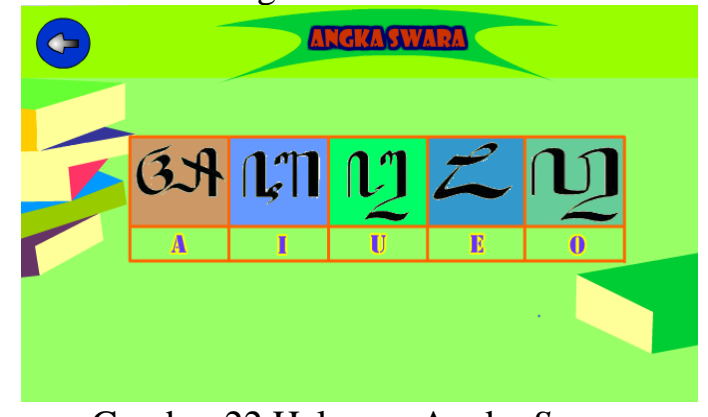

Gambar 22 Halaman Angka Swara

14. Halaman Sandhangan

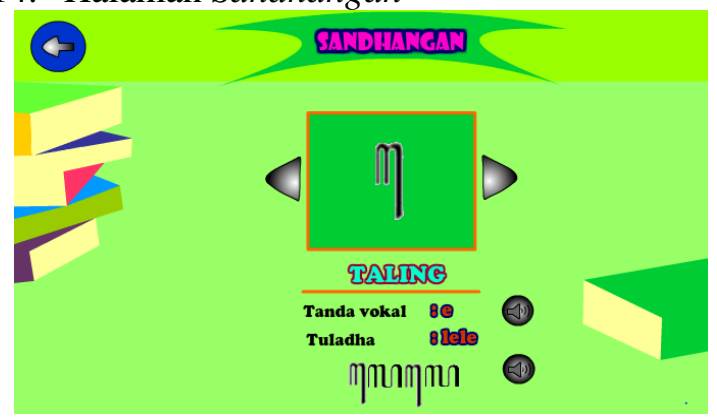

Gambar 23 Halaman Sandhangan 
15. Halaman Aksara Ganten

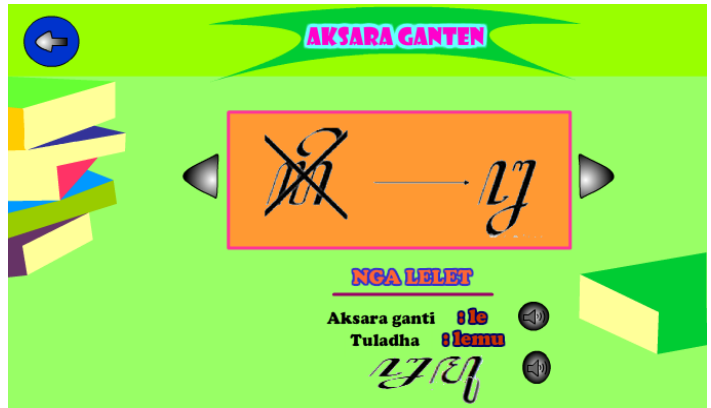

Gambar 24 Halaman Aksara Ganten

\section{Halaman Menu Game}

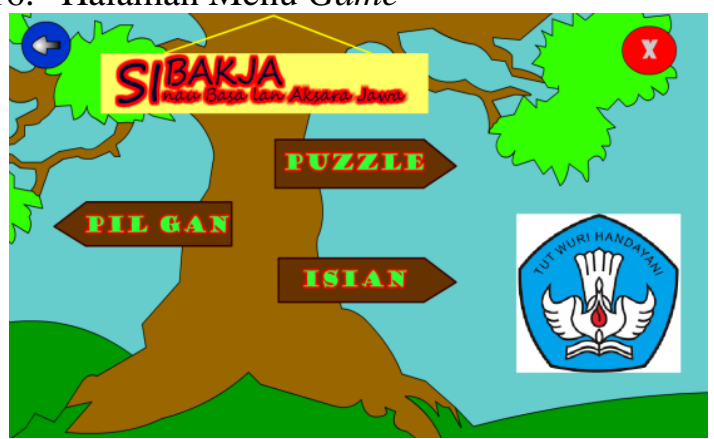

Gambar 25 Halaman Menu Game

\section{Halaman Level Puzzle}

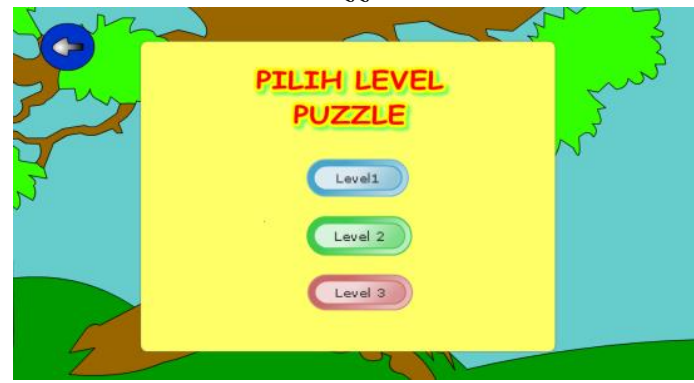

Gambar 26 Halaman Level Puzzle

18. Halaman Petunjuk Permainan Puzzle

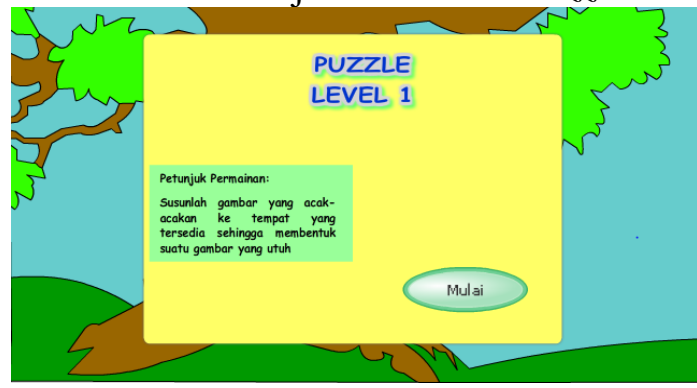

Gambar 27 Halaman Petunjuk Permainan Puzzle
19. Halaman Game Puzzle

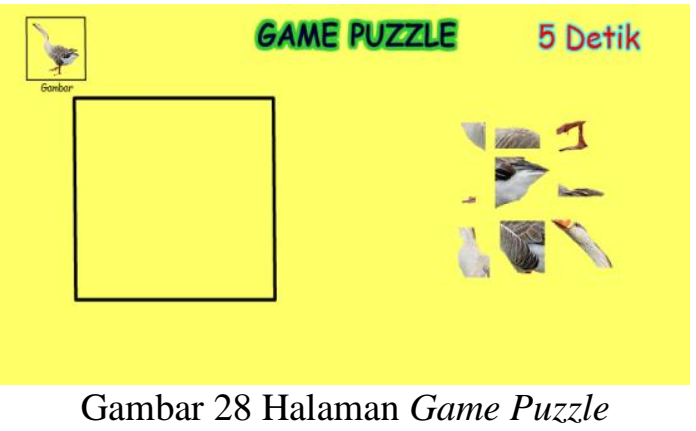

20. Halaman Hasil Game Puzzle

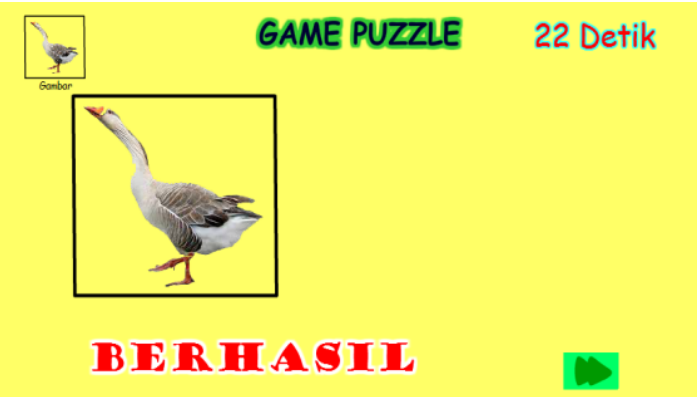

Gambar 29 Halaman Hasil Game Puzzle

21. Halaman Menu Pil Gan

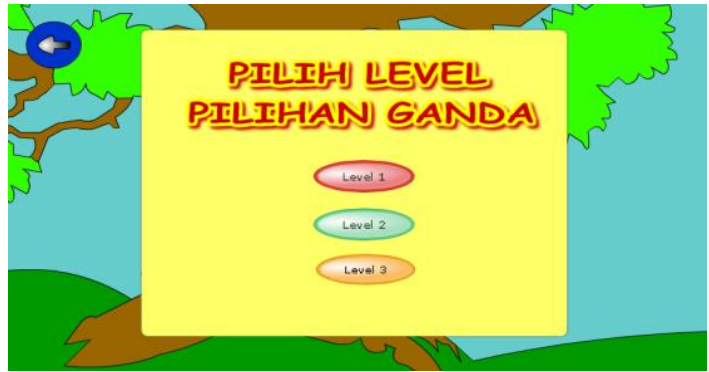

Gambar 30 Halaman Menu Pil Gan

22. Halaman Petunjuk Permainan Pil Gan

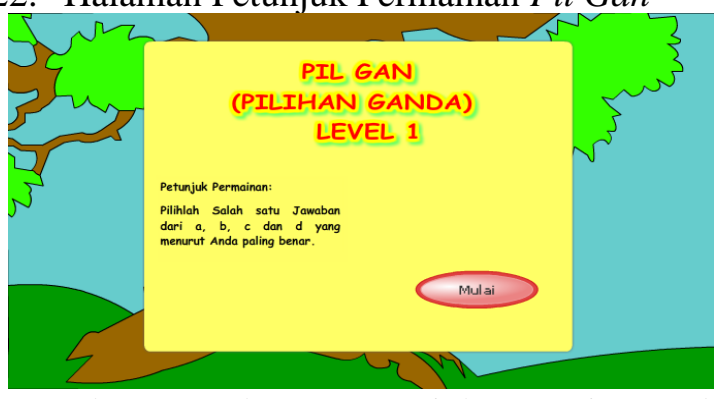

Gambar 31 Halaman Petunjuk Permainan Pil Gan 


\section{Halaman Pilihan Ganda}

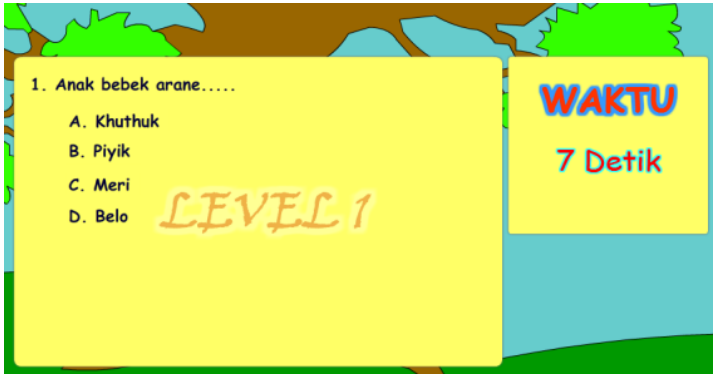

Gambar 32 Halaman Pilihan Ganda

24. Halaman Pilihan Ganda Benar

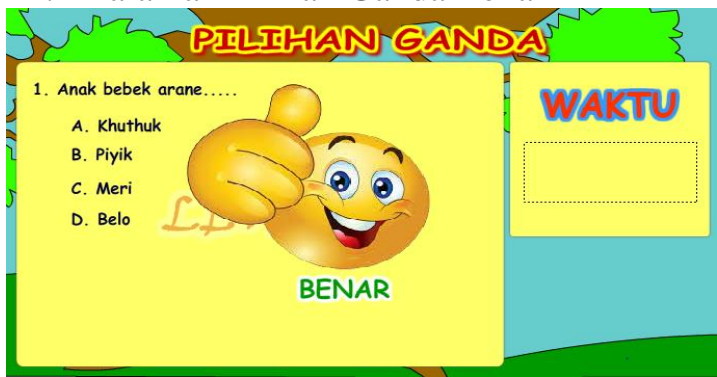

Gambar 33 Halaman Pilihan Ganda Benar

25. Halaman Pilihan Ganda Salah

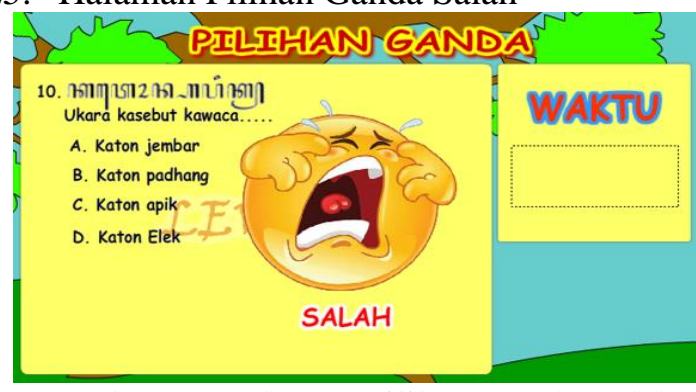

Gambar 34 Halaman Pilihan Ganda Salah

26. Halaman Skor Pilihan Ganda

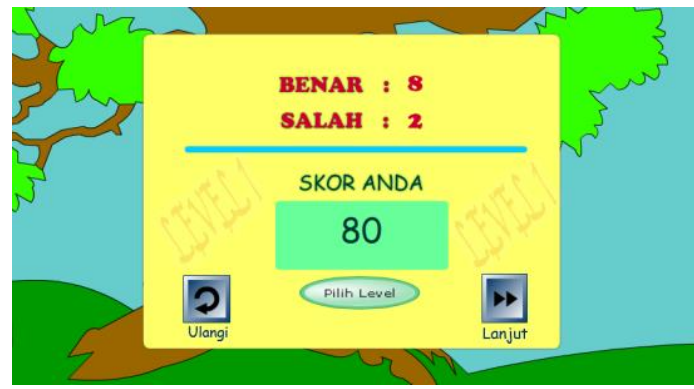

Gambar 35 Halaman Skor Pilihan Ganda
27. Halaman Menu Isian

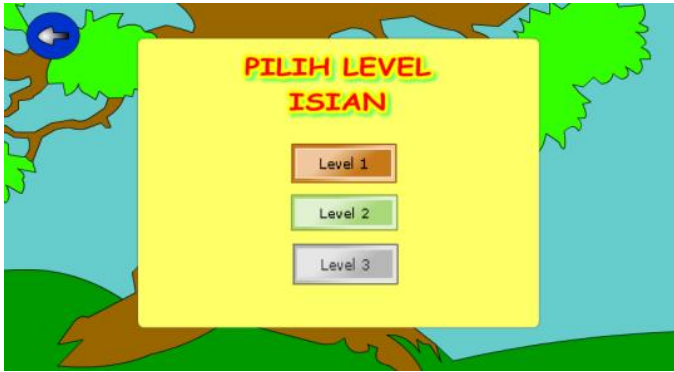

Gambar 52 Halaman Menu Isian

28. Halaman Petunjuk Permainan Isian

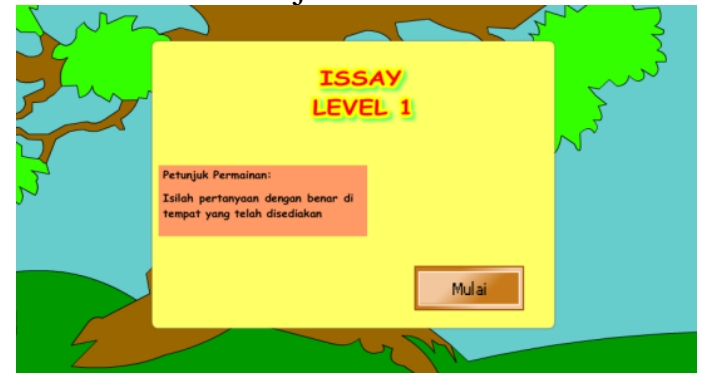

Gambar 36 Halaman Petunjuk Permainan Isian

29. Halaman Kuis Isian

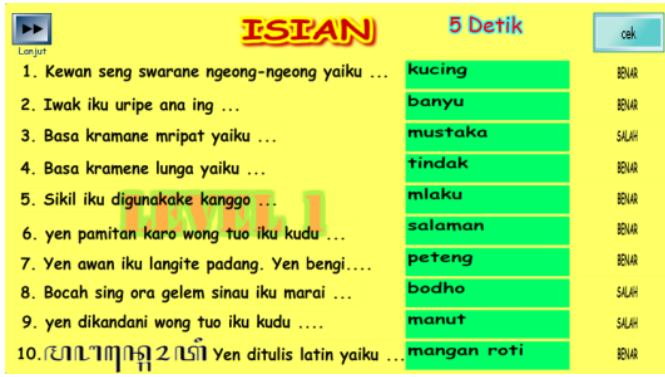

Gambar 37 Halaman Kuis Isian

30. Halaman Peringatan Waktu Isian

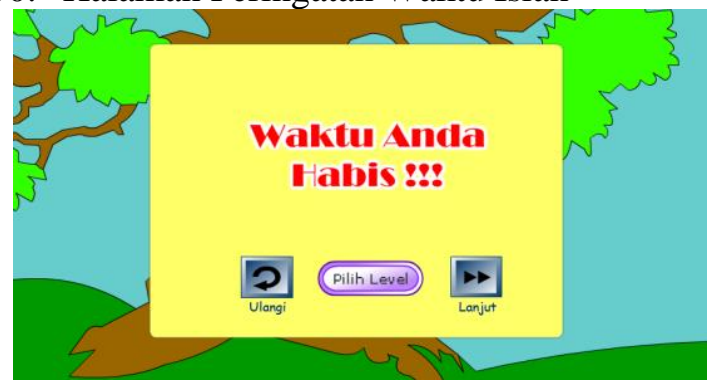

Gambar 38 Halaman Peringatan Waktu Isian 
31. Halaman Menu Keluar

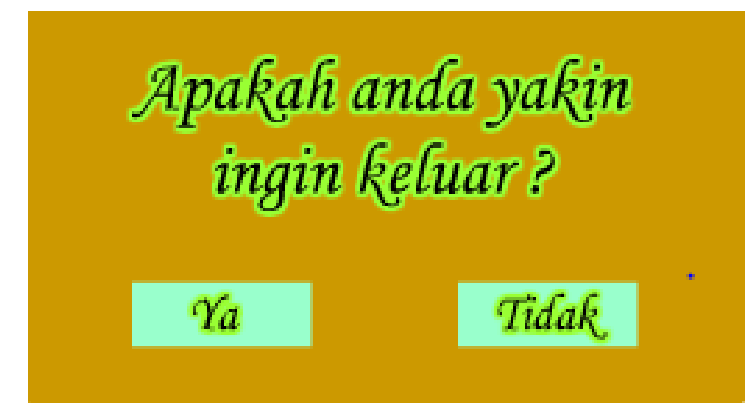

Gambar 39 Halaman Menu Keluar

\section{Kesimpulan Dan Saran}

\section{Kesimpulan}

Setelah melakukan penelitian dan perancangan game edukasi Sinau Basa dan Aksara Jawa (Sibakja), dapat diambil kesimpulan sebagai berikut :

1. Telah dihasilkan aplikasi edukasi berbasis android untuk membantu siswa belajar dalam belajar bahasa dan aksara jawa.

2. Game ini menggunakan tampilan menu dan tombol yang sangat sederhana, sehingga pemakai tidak akan kesulitan mengoperasikan game tersebut.

3. Aplikasi game edukasi ini dapat membantu menunjang daya ingat siswa karena dilengkapi dengan gambar dan suara, sehingga siswa dapat belajar dengan lebih mudah dan menyenangkan.

4. Berdasarkan survey dan kuisioner materi yang terdapat pada program aplikasi sesuai dengan materi yang dibutuhkan.

\section{Saran}

Berdasarkan hasil observasi dan penelitian, penulis menyarankan beberapa hal sebagai berikut:

1. Pengembangan game ini dapat dilakukan dari tampilannya.

2. Penambahan animasi yang lebih banyak akan membuat tampilan game ini lebih baik.

3. Program aplikasi Belajar Bahasa dan Aksara Jawa ini cocok untuk media belajar mandiri siswa.
4. Jumlah level dapat di tambah lagi agar tingkat kesulitan dalam memainkan game ini lebih banyak.

\section{Daftar Pustaka}

Agustina Candra and Tri Wahyudi. (2015). Aplikasi Game Pendidikan berbasis Android Untuk memperkenalkan Pakaian Adat Jawa. http://download.portalgaruda.org/article.p hp? article $=379143 \&$ val $=8382 \&$ title $=$ Apli kasi\%20Game\%20Pendidikan\%20Berbas is $\% 20$ Android $\% 20 \% 20$ Untuk $\% 20 \mathrm{Memp}$ erkenalkan\%20Pakaian\%20Adat\%20Indo nesia. (Diunduh pada tanggal 16 Maret 2018).

Anonim, a. developer android. http://developer.android.com/google/play services/index.html, diakses pada: 23 Mei 2018.

Arismadhani, dkk. 2013, Aplikasi Belajar Menulis Aksara Jawa Menggunakan Android, Jurusan Teknik Informatika, Fakultas Teknologi Informasi, Institut Teknologi Sepuluh Nopember (ITS), Surabaya.

Asrumiati. 2013. Adobe Flash CS6.Yogyakarta: Andi Wahana Komputer.

Arsenault, D. (2011:3) Video Game Genre, Evolution and Innovation. Eludamos Journal for Computer Game Culture.

Bambang, Hartono. 2013. Sistem Informasi Manajemen Berbasis Komputer. Jakarta: Rineka Cipta.

Brunette, Ed. 2010. Hello, Android. Pragmatic Bookshelf, United States of America.

Costikyan, Greg 2013, Uncertainty In Games, The MIT Press, Cambridge

Ekawati, Putri Ludfiah and Achmad Zakki Falani. (2014). Pemanfaatan Teknologi Game untuk Pembelajaran Mengenal Ragam Budaya Indonesia berbasis Android.

Fuada, Syifual. (2016). Perancangan Game Petualangan Pramuka Berbasis Android. http://download.portalgaruda.org/article.p hp? article $=418286 \& \mathrm{val}=8156 \&$ title $=$ PER ANCANGAN\%20GAME\%20PETUAL 
ANGAN\%20PRAMUKA\%20BERBASI S\%20ANDROID. (Diunduh pada 18 Maret 2018).

Harsono, 2011, Etnografi Pendidikan sebagai Desain Penelitian Kualitatif. Surakarta: Universitas Muhammadiyah Surakarta. https://www.google.co.id/search?q=mini mal+android+yang+digunakan+game+ad obe+flash + cs6\&oq=minimal + android + ya ng+digunakan+game+adobe+flash+cs6\& aqs $=$ chrome..69i57.31862j0j7\&sourceid $=$ chrome\&ie=UTF-8. (Diunduh pada 18 Maret 2018).

Hengky, Pramana W. 2010. Definisi Aplikasi.wikipedia.org/wiki/Aplikasi. Dilihat pada 24 Mei 2018.

Hurd, Daniel dan Jenuings, Erin. (2010), Standardized Educational Games Ratings: Suggested Criteria. Karya Tulis Ilmiah.

Jibril, A. (2011). Jurus Kilat Jago Adobe Flash. Yogyakarta: C.V Andi Offset.

Murya, Yosep. (2014). Pemrograman Android Black Box Jakarta: Jasakom.

Nandiwardhana, Indrayasa. Sri Yulianto and Jasson Prestiliano. (2012). Pengembangan Physics Game "FIX and FIT" Berbasis Android Smartphone Menggunakan Action Script 3.0 dan Quick Box 2D. http://ftiuksw.org/ejournal/assets/pdf/e22 1f87eb958b8470b10263427ecc54d.pdf. (Diunduh pada 18 Maret 2018).

Nazili Shaleh Ahmad. (2011). Pendidikan dan masyarakat: Kajian peran pendidikan dalam bidang sosial, politik, ekonomi, dan budaya. perkembangan pendidikan di negara maju, berkembang dan terbelakang Yogyakarta: Sabda Media.

Newman J. (2004). Video Games. London: Taylor and Francis Group.

Nugroho, Deni Aditra. Harmastuti and Uminingsih. (2017). Membangun Game Edukasi "MATHEMATIC MAZE" berbasis Android untuk Meningkatkan Kemampuan Berhitung pada Anak Sekolah Dasar. http://ftiuksw.org/ejournal/assets/pdf/e22 1f87eb958b8470b10263427ecc54d.pdf. (Diunduh pada 18 Maret 2018).
Nugroho. (2010). UML (Unfield Modeling Language), Yogyakarta: Penerbit Gava Media.

Subagyo. (2014). Pepak Basa Jawa, Yogyakarta : Kasih Media

Prensky, Marc. 2012. "From digital natives to digital wisdom: hopeful essays for 21st century learning". India: Corwin Press.

Pressman, R.S. 2010. Software Engineering: a practitioner's approach. 7th Edition. McGraw-Hill, New York.

Rosa, A.S dan M.Shalahuddin. 2014. Rekayasa Perangkat Lunak Struktur dan Berorientasi Objek. Bandung : Informatika.

Saroni, Muhammad. 2011. Manajemen Sekolah Kita Menjadi Pendidik Yang Kompeten. Yogyakarta: Ar-Ruzz Media.

Sharma, B dan Shah, J, K. (2012). A Study on Social Maturity, School Adjusment and Academic Achievement Among Residential School Girls. Journal of Education and Practice.

Supartinah. 2010. "Peningkatan Penguasaan Aksara Jawa Pada Siswa Kelas IV SDN Golo Pendekatan Cooperative Learning Tehnik Jigsaw dan Media Kartu Aksara”. Skripsi. Yogyakarta: FKIP UNY.

Sutabri, Tata. 2012. Analisis Sistem Informasi. Yogyakarta: Andi.

Stepth, Ellen. eHow Blog, 2010. dengan rujukan Priciples and Methods of Research. Ariola et al. (eds. 2006)

Zulfadli, Fahrul Rozi,. (2010). Mahir Membuat Game Dalam 1 Jam. Yogyakarta, Mitra Pelajar 